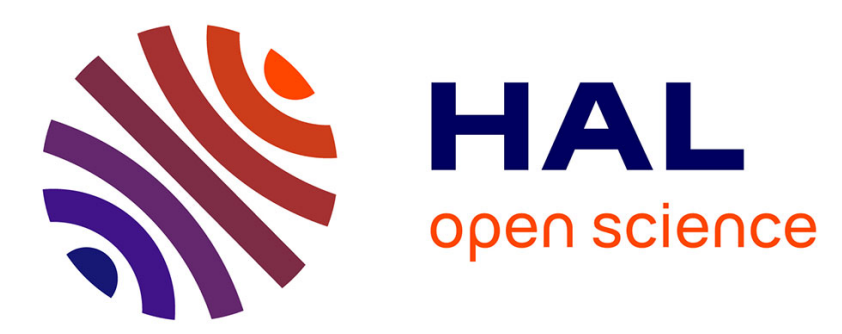

\title{
A new analytical solution to the mechanical behaviour of fully grouted rockbolts subjected to pull-out tests
}

\author{
Laura Blanco Martin, Faouzi Hadj Hassen, Michel Tijani
}

\section{To cite this version:}

Laura Blanco Martin, Faouzi Hadj Hassen, Michel Tijani. A new analytical solution to the mechanical behaviour of fully grouted rockbolts subjected to pull-out tests. Construction and Building Materials, 2010, 25 (2), pp.1-7. 10.1016/j.conbuildmat.2010.07.011 . hal-00526686

\section{HAL Id: hal-00526686}

https://hal-mines-paristech.archives-ouvertes.fr/hal-00526686

Submitted on 19 Oct 2010

HAL is a multi-disciplinary open access archive for the deposit and dissemination of scientific research documents, whether they are published or not. The documents may come from teaching and research institutions in France or abroad, or from public or private research centers.
L'archive ouverte pluridisciplinaire HAL, est destinée au dépôt et à la diffusion de documents scientifiques de niveau recherche, publiés ou non, émanant des établissements d'enseignement et de recherche français ou étrangers, des laboratoires publics ou privés. 


\section{A New Analytical Solution to the Mechanical Behaviour of Fully Grouted Rockbolts Subjected to Pull-out Tests}

Laura Blanco Martín ${ }^{1, *}$, Michel Tijani ${ }^{1}$, Faouzi Hadj-Hassen ${ }^{1}$

${ }^{1}$ Department of Geosciences, MINES ParisTech, 35 rue Saint-Honoré, 77305, Fontainebleau, FRANCE.

*Corresponding author (Ph.D. student). Telephone: +33 1646948 87; Fax: +331 64694951.

E-mail address: laura.blanco_martin@mines-paristech.fr

Abstract:

A new analytical approach able to predict the mechanical behaviour of fully grouted rockbolts subjected to pull-out tests is proposed in this paper. Input parameters of such approach are: bolt radius, bolt's Young modulus, displacement of the free end of the bolt and the constitutive law of the rockbolt-grout joint interface. The limited circumstances under which it is accurate to determine such constitutive law from pull-out tests are also presented. A solution for the load-displacement curve obtained during pull-out tests has been developed and is detailed in the case of a tri-linear bond-slip model. Comparison with experimental results obtained via in situ pull-out tests has led to the validation of this approach.

Keywords:

Analytical solution; bond-slip model; fully grouted rockbolts; joint interface; pull-out test.

\section{Introduction}

For the past 30 years, rockbolts have been widely used in civil and mining engineering. A rockbolt consists of a bar inserted in a borehole that is drilled into the surrounding soil or rock mass and anchored to it by means of a fixture. According to Windsor and Thompson [1], such a reinforcement system is comprised of four principal elements: the rock or soil, the reinforcing bar, the internal fixture to the borehole wall and the external fixture to the excavation surface (a plate and a nut in most cases). Worldwide experience and observations (Fuller and Hume [2]) have shown that the performance of a reinforcement system depends not only on the bar type and on the mechanical characteristics of the rock mass, but also on the properties of the internal and external fixtures, as well as on the fragmentation state of the surrounding ground.

In order to help the rock mass support itself (Rabcewicz et al. [3]), a load transfer mechanism takes place from unstable rock through the reinforcement system to stable rock. In this context, the internal fixture is of paramount importance because it couples the rock mass and the reinforcing rod together. Windsor [1] defined three types of reinforcement systems considering the load transfer concept: discretely 
mechanically or frictionally coupled (DMFC) systems, continuously frictionally coupled (CFC) systems and continuously mechanically coupled (CMC) systems. Accordingly, rockbolts anchored by a slit and wedge mechanism or an expansion shell belong to the DMFC system, Split-set and Swellex rockbolts belong to the CFC system and fully grouted rockbolts belong to the CMC system. In the latter case, the internal fixture is either a cement mortar or a resin-based grout, so that the strands of the bolt and the surrounding grouting material create a rock-joint like interface.

This paper deals with fully grouted rockbolts. The three main features of such reinforcement are (Fine [4], Chappell [5]):

- their capacity to stabilize jointed rock masses (thus to support unstable rock blocks), provided their far end is anchored to a stable zone;

- their confinement role, contributing to the use of the broken rock belt to confine the stable rock mass;

- the improvement that they induce in the mechanical properties of the rock mass, which restrains its deformation.

At the same time, the easy installation of the CMC rockbolts and their low cost compared to that of other reinforcement techniques have contributed to their worldwide spread in the past years. At the present time, the major concern remains the improvement of their design; for such purpose, a better understanding of the mechanical behaviour of fully grouted rockbolts is required, which can be achieved by means of field monitoring, laboratory and in situ testing, analytical approaches and numerical modelling.

In the 1970s, Freeman [6] monitored for the first time the loading process and the stress distribution along the embedded length of fully grouted rockbolts (Kielder experimental tunnel, UK). Since then, laboratory and in situ pull-out tests have shown that in most cases failure of fully grouted rockbolts takes place by debonding at either the bolt-grout or the grout-rock interface, provided the bolt has the right dimensions (Benmokrane et al. [7], Moosavi et al. [8], Ivanović and Neilson [9], Hagan [10]).

Regarding the numerical modelling, Ivanović and Neilson [9] have recently presented a non-linear bond-slip model to study the behaviour of rockbolts under dynamic loads.

As for the analytical approaches, Farmer [11] proposed in 1975 the first analytical solution to the behaviour of rockbolts under tensile forces. This essential work predicted that the axial load and the shear 
stress decrease exponentially from the loading point along the anchored length of the bolt (i.e., the length where the deformation is compatible across the interface). In the 1990s, Yacizi and Kaiser [12] emphasized the importance of dilation in the ultimate bond strength and developed the Bond Strength Model (BSM). Short later, Benmokrane et al. [7] proposed a tri-linear bond-slip model for the interfacial mechanism between the bolt and the grout. This model was based upon laboratory pull-out tests on both rock and cable bolts. More recently, Li and Stillborg [13] introduced the notion of the decoupling front, which moves from the loading point (when the applied force is large enough) towards the far end of the bolt gradually as the load increases. They also presented analytical solutions to both axial and shear stresses along the embedment length of $\mathrm{CFC}$ and $\mathrm{CMC}$ rockbolts during pull-out tests; nevertheless, they assumed a linear decrease of the shear stress in the plastic stage. In 2009, Ren et al. [14] proposed a fullrange analytical analysis of the mechanical behaviour of grouted rockbolts under tension loads. A trilinear bond-slip model was again considered for the rockbolt-grout joint interface. They compared their load-displacement predictions with in situ experimental data and the results were in quite good agreement; however, they assumed that the softening length is constant during the elastic-softeningdebonding stage.

These works are fundamental and have deeply contributed to a better understanding of the behaviour of rockbolts under tension loads, which has in turn led to a higher quality design, a reduction in costs and an increase in safety. Nonetheless, a complete solution able to predict the behaviour of fully grouted rockbolts under tension has not yet been offered.

The aim of this paper is to present such a complete solution taking into account a tri-linear constitutive law determined in advance. The pull-out test and the bond-slip model are presented first. Later, a closed-form solution for the prediction of the load-displacement curve issued from pull-out tests is developed. The restricted conditions under which a pull-out test is useful to determine the joint interface constitutive law are then described in detail. Finally, comparisons between the analytical solution and experimental data are shown, and the results are discussed.

\section{The pull-out test}

Pull-out tests are very useful to investigate the anchoring capacity of rockbolts. Design engineers conduct such tests to derive the shear stress as a function of the shear slip, provided the tests are carried out under accurate conditions (see section 5). 
Pull-out tests can be executed either in laboratory or in situ. Their principle is as follows: a borehole of radius $R_{r}$ and length $L$ (the embedment length) is drilled into the rock mass (or into a cement or rock sample in the case of laboratory tests) and a rockbolt of radius $R_{b}$, Young's modulus $E_{b}$ and longer than $L$ is anchored to it using a resin or cement grout. Once the grouting material has set, an axial tension load is applied to the bolt at the point where it protrudes from the borehole $(\mathrm{Z}=L)$. This is normally made by means of a hollow ram jack. The far end of the bolt $(Z=0)$ is free; thus the axial force at this point equals zero. In the case of laboratory tests, a confinement pressure can be applied around the rock or cement specimen to better reproduce the in situ conditions. Figure 1 shows the principal components of a pull-out test (laboratory setup).

When failure takes place at either the bolt-grout interface or the grout-rock interface, a shear stress $\tau$ develops on the lateral surface of the bolt in response to the applied axial load. This will assure stability as long as the axial load verifies $F \leq 2 \pi R_{b} \int \tau d Z$. Once the ultimate bearing capacity has been reached, the axial force will start to decrease. Figure 2 shows the stress distribution in an elementary length $d Z$.

During a pull-out test, at least two measures should be monitored in order to be able to exploit the test results: the axial load and the axial displacement at $Z=L$. Pull-out tests can be conducted under either axial displacement control or axial load control. The use of strain gauges along the embedment length would lead to the monitoring of the axial force as a function of the distance to the loading point. This is very valuable information for the validation of the analytical approaches.

In practice, laboratory tests are preferred to in situ tests because they are cheaper and easier to control. Besides, laboratory pull-out tests allow studying the influence of different parameters (such as the confinement pressure or the grout quality) on the bond strength. However, in situ tests are very helpful to know whether the bolt and the grout in use are compatible with the mechanical properties of the surrounding rock mass and its degree of damage.

\section{Bond-slip model}

The decoupling or debonding mechanism at the interface is represented by a bond-slip model (shear stress-shear slip relationship). A bond-slip model is a rheological characteristic of the joint between the rockbolt and the grouting material (or between the grouting material and the rock mass) and it can be established from pull-out tests results. Within the context of the ongoing Ph.D. thesis, a broad laboratory 
pull-out test campaign will be soon carried out for such purpose on both rockbolts and cable bolts and the results will be published later.

In order to develop analytical solutions to the behaviour of bolts subjected to tensile loads, the bondslip characteristic should be known in advance. In this paper, a tri-linear bond-slip model has been chosen as the constitutive law of the bolt-grout interface because literature (Benmokrane et al. [7], Guan et al. [15], Cai et al. [16], Xiao and Chen [17], Ren et al. [14]) has shown that it is widely accepted and good agreements between analytical solutions and experimental data have been obtained when it has been considered.

Basically, a tri-linear model (see figure 3) consists of a first positive slope segment from $\left(u_{0}=0, \tau_{0}=0\right)$ to $\left(u_{1}, \tau_{1}\right)$ followed by a decreasing segment until $\left(u_{2}, \tau_{2}\right)$ and then a horizontal plateau. The ascending branch represents elasticity (i.e., the interface is totally coupled) and $\tau_{l}$ corresponds to the peak shear stress. The negative slope stretch corresponds to a softening behaviour of the interface and the horizontal branch represents the residual resistance $\left(\tau_{2}=\tau_{3}\right)$ that remains due to friction once debonding has occurred.

\section{Basis of the proposed analytical approach and equations}

\subsection{System equations}

The aim of this section is to determine analytically the full range behaviour of a grouted rockbolt throughout the duration of a pull-out test. Therefore, expressions for both the axial force and the axial displacement at point $Z=L$ will be obtained by the end of this part.

Hereafter, the reference axis will be set in the joint interface, so that $Z=0$ corresponds to the far end of such joint and $Z=L$ corresponds to the point where the load is applied. We shall consider two different cases concerning the evolution of the embedment length:

- $\quad k=0$ if the embedment length does not change. This means that at $Z=0$ the bolt exceeds the borehole sufficiently, so that the contact between the grouting material and the rockbolt is made along $Z \in[0, L]$ for the entire duration of the test (i.e., the length of the joint between the bolt and the grout does not change). Then, we can define the variable $T \geq 0$ as the axial displacement of the bolt at the position $Z=0$;

- $k=1$ if the contact length between the bolt and the grouting material decreases throughout the test: at the beginning $(T=0)$, the free end of the rockbolt is at point $Z=k T=0$. As the test 
progresses $(T>0)$, the free end will move towards $Z=L$ and the contact will be made along $Z \in[T, L]$ (i.e., the joint length decreases).

Let $W(Z, T)$ be the axial displacement of the bolt cross-section that is in front of point $Z$ of the joint interface. The axial deformation of the rockbolt is $W^{\prime}=\frac{\partial W}{\partial Z}$. Let $F$ be the axial force on the bolt, which decreases along the embedment length from its maximum value at $Z=L$ to a null value at the free end, $Z=k T$.

According to figure 2, the equilibrium equation of the system at any moment is given by:

$d F-2 \pi R_{b} \tau d Z=0$

We shall accept henceforth that the shear slip $U(Z, T)$ at the joint interface (i.e., the relative displacement between the rockbolt and the grouting material) equals the axial displacement of the rockbolt $W(Z, T)$. This simplification is justified because the axial deformation of the bolt, $W^{\prime}$, is $<<1$. We shall assume as well that the bolt remains within the elastic range during the whole pull-out test. Thus the constitutive equations for the interface joint and the rockbolt are respectively:

$\tau=S(W)$

$F(z)=\pi R_{b}^{2} \sigma_{b}(z)=\pi R_{b}^{2} E_{b} W^{\prime}$

In accordance to Eq. (3), once $W^{\prime}$ is known, the axial force $F$ is also known. The pull-out test is then completely characterised by $W(L, T)$ and $W^{\prime}(L, T)$.

The constitutive law of the joint is $\tau=S(W)$. It describes the local relationship between the shear stress at the interface and the axial displacement $W(Z, T)$. As stated before, such constitutive law is a joint property and it is only applicable in the case of a monotonous solicitation, which means that $\forall Z \in[k T, L]$ the axial displacement must be an increasing function of time. Given that the variable $T$ increases with time and that it equals the axial displacement $W$ at point $Z=k T$ (the free end of the bolt), it can be used as a cinematic time.

Furthermore, in practice $S(W)$ is a continuous function defined as follows: $S(W)>0$ for $W>0$ and $S(W)=0$ otherwise. Its derivative $S^{\prime}(W)=\frac{d S}{d W}$ is a piecewise-defined function that verifies: $S^{\prime}>0 \Rightarrow S^{\prime \prime} \leq 0$.

Combining the last three equations, the governing equation of the pull-out test problem is:

$W^{\prime \prime}=\frac{2}{E_{b} R_{b}} S(W)$ 
The problem is thereby reduced to find the axial displacement $W$ (as a function of $Z$ ) that solves Eq. (4).

Boundary conditions are:

$W(k T, T)=T$

$W^{\prime}(k T, T)=0$

Since the aforementioned boundary conditions do not depend on point $Z=L$ (they are both related to the free end of the rockbolt), it is possible to solve Eq. (4) for $Z \in[k T,+\infty[$. Actually, the innovation of the new approach proposed in this paper to solve the pull-out test problem lies in not using boundary conditions relating to $Z=L$.

On the other hand, the condition $W(k T, T)=T$ together with $T>0$ allow the use of the variable $T$ as the only key parameter during the pull-out test.

To sum up, data needed to solve the problem given by (4) with boundary conditions (5) are: $k, T, R_{b}$, $E_{b}$ and the joint constitutive law $S(W)$. A complementary condition is $\frac{\partial W}{\partial T} \geq 0 \forall Z \in[k T, L]$. The determination of the displacement of the free end of the bolt, $T$, will be discussed in section 5 .

The approach to the problem presented above is also valid when failure takes place at the grout-rock interface; in such case, an appropriate joint constitutive law, the borehole radius and an equivalent material Young's modulus should be used. Anyway, the mathematical problem remains the same.

\subsection{Resolution method}

The problem will be solved using reduced variables because this leads to a generalised solution. The new variables are therefore:

$$
\begin{aligned}
& z=\frac{Z}{R_{b}} \\
& t=\frac{T}{R_{b}} \\
& w(z, t)=\frac{W(Z, T)}{R_{b}} \\
& f(w)=\frac{2 S(W)}{E_{b}}
\end{aligned}
$$

Thus the new differential equation is:

$$
w^{\prime \prime}=f(w)
$$

with the following boundary conditions pertaining to $z=k t$ : 
$w(k t, t)=t$

$w^{\prime}(k t, t)=0$

and the complementary condition $\frac{\partial w}{\partial t} \geq 0 \forall z \in\left[k t, L / R_{b}\right]$. The pull-out test is now characterised by $w\left(L / R_{b}, t\right)$ and $w^{\prime}\left(L / R_{b}, t\right)$.

Inasmuch as $w^{\prime \prime} \geq 0, w^{\prime}$ is an increasing function $\forall z \in\left[k t,+\infty\left[\right.\right.$. Moreover $w^{\prime}(k t, t)=0$; therefore $w^{\prime} \geq 0$ $\forall z \in[k t,+\infty[$. This means that $w$ is an increasing function too, and given that $w(k t, t)=t \geq 0$, it follows that $w \geq 0 \forall z \in[k t,+\infty[$.

In order to solve the problem easily, Eq. (10) may be multiplied by $w^{\prime}$. Let $g(w)$ be the increasing positive function defined as:

$g(w)=2 \int_{0}^{w} f(u) d u$

Therefore, function $g(w)$ is known as far as the behaviour of the interface is known.

The two last transformations lead to:

$\frac{\partial\left(w^{\prime}\right)^{2}}{\partial z}-\frac{\partial g(w)}{\partial z}=0 \Rightarrow \frac{\partial}{\partial z}\left(\left(w^{\prime}\right)^{2}-g(w)\right)=0 \Rightarrow\left(w^{\prime}\right)^{2}-g(w)=C$

where $C$ is a constant. Taking the boundary conditions (11) and the fact that $w^{\prime} \geq 0$ into account, it comes that:

$C=-g(t)$

$w^{\prime}=\sqrt{g(w)-g(t)}$

The problem has been reduced to solving the first order differential equation given by (14) with the boundary condition $w(k t, t)=t$.

As long as $z>k t, w^{\prime}>0$ and as a result $w$ is a strictly increasing function with respect to $z$. This makes it possible to inverse the problem, and so to calculate $z$ as a function of $w$ :

$$
\begin{aligned}
& d z=\frac{d w}{\sqrt{g(w)-g(t)}} \\
& \int_{k t}^{z} d z=\int_{t}^{w} \frac{d u}{\sqrt{g(u)-g(t)}} \Rightarrow z-k t=\int_{t}^{w}[g(u)-g(t)]^{-1 / 2} d u=\zeta(w)
\end{aligned}
$$

In short, from the known function $f(w)$, the functions $g(w)$ and $\zeta(w)$ are calculated, and then, the inversion of $\zeta(w)$ permits the determination of the axial displacement $w$ and the axial deformation $w$ ' as a solely function of $t$ for a given $z$. This is what makes the approach innovative. 
A detailed explanation of this new solution is presented in the next paragraph. A tri-linear constitutive law has been considered for the rockbolt-grout joint interface.

\subsection{Analytical solution using a tri-linear bond-slip model}

In the case of a tri-linear constitutive law (see figure 3), the bond-slip model is characterised by four pairs in reduced variables $\left(w_{0}, f_{0}\right) \equiv(0,0),\left(w_{1}, f_{1}\right),\left(w_{2}, f_{2}\right)$ and $\left(w_{3}, f_{3}\right)$. These pairs divide the function $f(w)$ into three intervals that correspond to $] w_{i-1}, w_{i}$ [ for $i \in\{1,2,3\}$. Inside each interval $f_{i}^{\prime}$ is constant and then:

$$
f(w)=f_{i}+f_{i}^{\prime} \cdot\left(w-w_{i}\right)
$$

with

$$
f^{\prime}(w)=f_{i}^{\prime}=\frac{f_{i}-f_{i-1}}{w_{i}-w_{i-1}}
$$

Values for function $g(w)$ are $g_{i}=g\left(w_{i}\right)$ such that $\mathrm{g}_{0}=0$. For $i \in\{1,2,3\} g_{i}$ are calculated by integration:

$$
g_{i}=g_{i-1}+\left(f_{i}+f_{i-1}\right) \cdot\left(w_{i}-w_{i-1}\right)
$$

Similarly, inside each interval $] w_{i-l}, w_{i}[$ :

$$
g(w)=g_{i}+\left[f(w)+f_{i}\right] \cdot\left(w-w_{i}\right)
$$

In order to solve the integral $\int[g(w)-g(t)]^{-1 / 2} d w$, function $h(w)>0$ is defined as follows:

$$
h(w)=f(w)^{2}-f^{\prime}(w) \cdot[g(w)-g(t)]
$$

with

$h^{\prime}(w)=-f^{\prime \prime}(w) \cdot[g(w)-g(t)]=0$

Hence, inside each interval $] w_{i-1}, w_{i}[$ :

$$
h(w)=h_{i}(t)=f_{i}^{2}-f_{i}^{\prime} \cdot\left[g_{i}-g(t)\right]>0
$$

And so, for $] w_{i-1}, w_{i}[, \quad i \in\{1,2,3\}$ :

- If $f^{\prime}{ }_{i} \neq 0: g(w)-g(t)=\frac{f(w)^{2}-h_{i}(t)}{f_{i}^{\prime}}$ and $d w=\frac{d f}{f_{i}^{\prime}}$

- If $f_{i}^{\prime}=0: g(w)-g(t)=g_{i}+2 f_{i} \cdot\left(w-w_{i}\right)-g(t)$

In the same way, the evolution of the reduced axial displacement of the free end of the bolt, which is represented by the control parameter $t>0$, is described by $w_{j-1} \leq t \leq w_{j}, j \in\{1,2,3\}$. Thus for $] w_{j-1}, w_{j}[$ :

$$
\begin{aligned}
& f(t)=f_{j}+f_{j}^{\prime} \cdot\left(t-w_{j}\right) \\
& f^{\prime}(t)=f_{j}^{\prime}
\end{aligned}
$$


$g(t)=g_{j}+\left[f(t)+f_{j}\right] \cdot\left(t-w_{j}\right)$

Let's focus now on function $\zeta(w)=\int_{t}^{w}[g(u)-g(t)]^{-1 / 2} d u$. Given that for $w^{\prime}>0$ the reduced axial displacement $w$ is a strictly increasing function with respect to $z$, it comes that $w(z, t)>t$ for $z>k t$. As for the two indices that characterize the discretisation of the bond-slip model, $] w_{m-l}, w_{m}[$ where $m=\{i, j\}$, this implies that $i \geq j$, meaning that the displacement of any point $\left.z \in] k t, L / R_{b}\right]$ is bigger than the displacement of the free end of the bolt, $t$, even if they are both in the same interval $] w_{m-1}, w_{m}[$. The function $\zeta(w)$ is then defined by the series $\zeta_{0}=0<\zeta_{1}<\zeta_{2}<\zeta_{3}$, where:

- $\quad$ For $i<j: \zeta_{i}=0$

- For $i=j: \zeta_{j}=\int_{t}^{w_{j}}[g(u)-g(t)]^{-1 / 2} d u$

- For $i>j: \zeta_{i}=\zeta_{i-1}+\int_{w_{i-1}}^{w_{i}}[g(u)-g(t)]^{-1 / 2} d u$

Thus $\zeta_{i}, i \in\{1,2,3\}$, are only function of $t$. From a physical point of view, they represent the evolution during the pull-out test of the boundary position $z_{i}$ of each characteristic stage of the bond-slip model (represented by $] w_{i-1}, w_{i}[$ ) with respect to the free end of the rockbolt, $z=k t$. Since the maximum axial force occurs at $z=L / R_{b}$, every possible behaviour of the interface will start at this point and move downwards to $z=k t$. The extension of the embedment length that is currently "occupied" by each stage (i.e., elasticity, plasticity or residual behaviour) during the test is given by $\zeta_{i}$. Thereby, $\zeta_{I}$ represents the spatial evolution of the boundary of the elastic domain: as the test goes on (i.e., as $t$ increases), this boundary will move downwards from $z=L / R_{b}$ to $z=k t$ and arrive at the free end when $t=w_{l}$. As $\zeta_{l}$ moves towards $z=k t, \zeta_{2}$ and $\zeta_{3}$ will progressively appear at $z=L / R_{b}$ and move in turn towards the free end of the rockbolt.

Three scenarios are possible for solving $\int[g(w)-g(t)]^{-1 / 2} d w$ in either $\left[w_{i-1}, w_{i}\right]$ or $\left[t, w_{j}\right]$. Let $\left[w_{a}, w_{b}\right]$ be a generic interval :

- If $f_{b}^{\prime}>0: \int_{w_{a}}^{w_{b}}[g(u)-g(t)]^{-1 / 2} d u=\frac{\arccos h\left(f_{b} / \gamma\right)-\arccos h\left(f_{a} / \gamma\right)}{\beta}$

- If $f^{\prime}{ }_{b}<0: \int_{w_{a}}^{w_{b}}[g(u)-g(t)]^{-1 / 2} d u=\frac{\arccos \left(f_{b} / \gamma\right)-\arccos \left(f_{a} / \gamma\right)}{\beta}$

- If $f_{b}^{\prime}=0: \int_{w_{a}}^{w_{b}}[g(u)-g(t)]^{-1 / 2} d u=\frac{\sqrt{g_{a}+2 f_{a}\left(w_{b}-w_{a}\right)-g(t)}-\sqrt{g_{a}-g(t)}}{f_{a}}$

Where constants $\beta$ and $\gamma$ are defined as: $\beta=\sqrt{\left|f_{b}^{\prime}\right|}$ and $\gamma=\sqrt{h_{b}(t)}$. 
The development of the analytical solution for a given $z$ (i.e., the position where the axial force and the axial displacement are to be determined) involves consequently the following steps:

1. Calculating $\zeta_{i}, i \in\{1,2,3\}$ for $i \geq j(j \in\{1,2,3\})$ according to Eqs. (28), (29) and (30). The analytical development of such functions is helped by Eqs. (31), (32) and (33) as appropriate. All the values required can be obtained using Eqs. (17), (18), (22), (25), (26) and (27);

2. Finding $\zeta_{i}$ such that $\zeta_{i-1}<z-k t<\zeta_{i}$. The axial displacement $w(z, t)$ will be therefore inside $\left[w_{i-1}, w_{i}\right]$. It is important to note that this inequality is likely to be satisfied more than once for each $j$ (i.e., for each interval $w_{j-1} \leq t \leq w_{j}$ ). In such case, the intersection between $z-k t$ and $\zeta_{i}$ defines the value $t_{i}$ at which the behaviour of the interface shifts from the current interval $\left[w_{i-1}, w_{i}\right]$ to the next one (from elasticity to plasticity, for instance);

3. Calculating $z-k t-\zeta_{i}=\int_{w_{i}}^{w}[g(u)-g(t)]^{-1 / 2} d u$. Again, Eqs. (31), (32) and (33) are used as appropriate;

4. Inversing the last expression leads to the determination of $f(w)$ if $f^{\prime} \neq 0$ and to the determination of $w$ if $f^{\prime}=0$. In the former case, integration of $f(w)$ gives $w^{\prime}$ and $w$ can be determined by:

$$
w=w_{i}+\frac{f(w)-f_{i}}{f_{i}^{\prime}}
$$

In the later case, derivation of $w$ with respect to $z$ gives $w$ '.

A new analytical solution to the pull-out test problem is henceforth available. A prediction of the load-displacement curve is supplied by the last equations applied to point $z=L / R_{b}$.

\section{Determination of the constitutive law of the joint}

The bond-slip model can be derived from the load-displacement curve obtained in a pull-out test. This is a crucial step in the design of fully grouted rockbolts. The influence of various parameters such as the grout quality, the borehole-to-rockbolt-diameter ratio, the confinement pressure and the borehole roughness can be studied through the realisation of these tests and the most influencing parameters can then be determined. Since the constitutive law is a rheological property of the rockbolt-grout joint (or grout-rock joint), it does not depend on the embedment length. Therefore, the validation of the bond-slip model can be carried out by conducting two pull-out tests under identical conditions but with different anchoring lengths. 
Monitoring of a pull-out test provides the following data: $w^{\prime}\left(L / R_{b}, t\right)$ and $w\left(L / R_{b}, t\right)$. Eq. (14) can then be written as:

$$
w^{\prime}\left(L / R_{b}, t\right)=\sqrt{g\left(w\left(L / R_{b}, t\right)\right)-g(t)}
$$

The relationship between $f(w)$ and $g(w)$ would yield to the determination of the constitutive law:

$$
g(w)=2 \int_{0}^{w} f(u) d u \Rightarrow f(w)=\frac{g^{\prime}(w)}{2}
$$

However, even if $t$ (displacement of the free end of the bolt) were monitored, it would be in general not possible to deduce a single expression for $g(w)$. There are two extreme cases where $f(w)$ can be unequivocally determined:

- $\quad$ The embedment length is long enough, so that $t$ is negligible with respect to $w\left(L / R_{b}, t\right)$. In this case,

$\left[w^{\prime}\left(L / R_{b}, t\right)\right]^{2} \approx g\left(w\left(L / R_{b}, t\right)\right)$

- The embedment length is short enough to ensure a uniform distribution of the shear stress $f(w)$ in $\left[k t, L / R_{b}\right]$. This is the typical case in laboratory setups. It comes that:

$$
f\left(w\left(L / R_{b}, t\right)\right) \approx \frac{w^{\prime}\left(L / R_{b}, t\right)}{L / R_{b}-k w\left(L / R_{b}, t\right)}
$$

As it can be seen, in none of the two situations is the displacement of the free end of the bolt needed.

Besides, it is important to note that, in general, in situ pull-out tests do not allow the determination of an accurate constitutive law for the rockbolt-grout interface.

\section{Application examples}

The current section is devoted to the comparison between experimental data, issued from pull-out tests, and the analytical solution proposed in section 4 . The objective here is therefore to validate the offered approach. Two in situ pull-out tests are discussed.

\subsection{In situ pull-out test on a 5 m long strand rockbolt}

Chen and Ren [18] carried out a pull-out test on a novel steel strand rockbolt whose properties were: $R_{b}=7.63 \mathrm{~mm}, E_{b}=200 \mathrm{GPa}$ and $L=5 \mathrm{~m}$. The parameters of the tri-linear bond-slip model are:

$W_{l}=1.4497 \mathrm{~mm}, W_{2}=12.5895 \mathrm{~mm}, S_{I}=1.62 \mathrm{MPa}$ and $S_{2}=0.34 \mathrm{MPa}$. This set of parameters has been obtained by a good fit of the experimental data using the analytical solution presented in this paper. Considering the length announced, the case where $k=0$ has been chosen. According to subsection 4.3 , the data derived 
from such bond-slip model and needed for the application of the new analytical solution are presented in table 1. In this case, $z=L / R_{b}=655.31$. It should be noted that, since the third interval of the bond-slip model is a horizontal plateau, the value of $w_{3}$ is only dependent on the amount of axial displacement that takes place during the pull-out test.

\begin{tabular}{ccccccccccc}
\hline$w_{1}$ & $w_{2}$ & $w_{3}$ & $f_{1}$ & $f_{2}=f_{3}$ & $f_{l}^{\prime}$ & $f_{2}^{\prime}$ & $f_{3}^{\prime}$ & $g_{1}$ & $g_{2}$ & $g_{3}$ \\
\hline 0.19 & 1.65 & 5.00 & $1.62 \mathrm{e}-05$ & $3.40 \mathrm{e}-06$ & $8.53 \mathrm{e}-05$ & $-8.77 \mathrm{e}-06$ & 0.00 & $3.08 \mathrm{e}-06$ & $3.17 \mathrm{e}-05$ & $5.45 \mathrm{e}-05$ \\
\hline
\end{tabular}

Table 1: Useful data for the application of the new approach to Chen and Ren's in situ pull-out test [18]

As stated in step 1 (see subsection 4.3), the functions $\zeta_{i}(i \in\{1,2,3\})$ are calculated for each interval $w_{j-1} \leq t \leq w_{j}(j \in\{1,2,3\})$. Steps 2,3 and 4 are then accomplished and the axial displacement $w$ and the axial deformation $w^{\prime}$ are sequentially obtained as a function of $t$ in $z=L / R_{b}$ according to the progress of the bond-slip model at such point (namely elasticity, plasticity and residual behaviour).

This pull-out test has also been studied by Ren et al. [14], who declared the following bond-slip model for the same experimental data: $W_{l}=2.56 \mathrm{~mm}, W_{2}=6.67 \mathrm{~mm}, S_{l}=2.3 \mathrm{MPa}$ and $S_{2}=0.414 \mathrm{MPa}$. Comparison between these two different constitutive laws is shown in figure 4. Differences arise from the fact that Ren et al. [14] used their analytical approach simultaneously for two purposes: predicting the load-displacement behaviour of the rockbolt and determining two out of the four parameters of the constitutive law. It is the authors' belief that, in order to analytically predict the load-displacement behaviour of rockbolts subjected to pull-out tests, the whole bond-slip model should be known in advance.

Figure 5 compares the experimental results (crosses) with the analytical solution proposed in this paper and with the analytical solution proposed by Ren et al. [14]. The two bond-slip sets of parameters presented above have been considered respectively.

Furthermore, one of the phases of Ren et al.'s analytical approach is characterised by a decrease of both the axial displacement and the axial force. Ren et al. [14] stressed that this phenomenon cannot be captured in real pull-out tests, neither force nor displacement controlled. The authors of this paper would like to emphasize that, in the new mathematical model presented here such phenomenon has not been taken into account because the new approach is only valid when the axial displacement is an increasing 
function of time. Figure 6 shows our proposal for the complete physical solution to the pull-out test problem.

\subsection{In situ pull-out test on a $1 \mathrm{~m}$ long threaded steel bar}

In this case, the pull-out test was conducted by Rong et al [19]. Concrete was used as grouting material. The rockbolt properties were: $R_{b}=16 \mathrm{~mm}, E_{b}=210 \mathrm{GPa}$ and $L=1 \mathrm{~m}$. The parameters of the trilinear bond-slip model obtained via the new analytical approach to best fit the experimental data are: $W_{l}=0.096 \mathrm{~mm}, W_{2}=0.816 \mathrm{~mm}, S_{l}=5.24 \mathrm{MPa}$ and $S_{2}=0.524 \mathrm{MPa}$. Once again, the case where $k=0$ was chosen. The derivation of the data needed for the application of the new analytical solution and the process undertaken to predict the load-displacement curve is the same than in the previous example.

The bond-slip parameters proposed by Ren et al. [14] are: $W_{I}=0.19 \mathrm{~mm}, W_{2}=0.53 \mathrm{~mm}, S_{I}=8.1 \mathrm{MPa}$ and $S_{2}=0.729 \mathrm{MPa}$. These two sets of parameters are represented in figure 7 .

The comparison between the experimental data (circles), Ren et al.'s [14] approach and the current analytical approach can be seen in figure 8 .

\section{Conclusions}

A new analytical approach for the mechanical behaviour of fully grouted rockbolts subjected to pullout tests has been proposed in this paper. This theoretical approach provides a complete solution to predict and to understand the behaviour of fully grouted rockbolts under tensile loads.

The originality of this approach lies in the fact that the boundary conditions do not concern the point where the load is applied; they solely concern the free end of the bolt. This allows using the displacement of the mentioned extremity as the only key parameter to predict the load-displacement behaviour throughout a pull-out test.

Experimental results issued from two different in situ pull-out tests have been compared to the predictions of the new analytical approach and the results are very satisfactory. A tri-linear bond-slip model has been used in both cases to characterize the rockbolt-grout interface.

A compelling insight into the determination of the constitutive law of the joint between the rockbolt and the grout (or between the grout and the surrounding rock mass) has also been presented and it has been demonstrated that only short embedment lengths are useful to the derivation of such law. For such purpose, a wide laboratory pull-out test campaign will be soon conducted by the authors. 


\section{Acknowledgments}

This research work has been carried out within the framework of the European programme RFCS (PROSAFECOAL project). The collaboration, discussions and knowledge exchanged between partners, in addition to the technical visits attended during the coordination meetings have invaluably contributed to the fulfilment of this work. 


\section{References:}

[1] Windsor C.R., Thompson A.G. Rock reinforcement-technology, testing, design and evaluation. Comprehensive Rock Engineering (Ed. J.A. Hudson). Pergamon Press: Oxford (1993).

[2] Fuller P.G., Hume B.G., Hume R.G. Bolt load simulation and its practical application. Rock mechanics, Aubertin, Hassani\&Mitri (eds). Balkema, Rotterdam (1996). ISBN 905410838 X.

[3] Rabcewicz L. The New Austrian Tunnelling Method (1964).

[4] Fine J. Le soutènement des galeries minières. Les Presses de l'Ecole des Mines de Paris (1998).

[5] Chappell B.A. Rock bolts and shear stiffness in jointed rock mass. Journal of Geotechnical and Geoenvironmental Engineering, vol 115 (1989).

[6] Freeman T.J. The behaviour of fully-bonded rock bolts in the Kielder experimental tunnel. Tunnels and Tunnelling: 37-40 (June 1978).

[7] Benmokrane B., Chennouf A., Mitri H.S. Laboratory Evaluation of Cement-Based Grouts and Grouted Rock Anchors. International Journal of Rock Mechanics and Mining Science, vol 32: 633-642 (1995).

[8] Moosavi M., Jafari A., Khosravi A. Bond of cement grouted reinforcing bars under constant radial pressure. Cement and Concrete Composites, vol 27: 103-109 (2005).

[9] Ivanović A., Neilson R.D. Modelling of debonding along the fixed anchor length. International Journal of Rock Mechanics and Mining Science, vol 46: 699-707 (2009).

[10] Hagan P.C. Variation in load transfer of a fully encapsulated rockbolt. Proceedings $23^{\text {rd }}$ International Conference on Ground Control in Mining. Morgantown, Australia (2004).

[11] Farmer I.W. Stress Distribution along a Resin Grouted Rock Anchor. International Journal of Rock Mechanics and Mining Science, vol 12: 347-351 (1975).

[12] Kaiser P.K., Yacizi S. Bond Strength of Grouted Cable Bolts. International Journal of Rock Mechanics and Mining Science, vol 29: 279-292 (1992).

[13] Li C., Stillborg B. Analytical models for rock bolts. International Journal of Rock Mechanics and Mining Science, vol 36: 1013-1029 (1999).

[14] Ren F.F., Yang Z.J., Chen J.F., Chen W.W. An analytical analysis of the full range behaviour of grouted rockbolts based on a tri-linear bond-slip model. Constr Build Mater (2009), doi:

10.1016/j.conbuildmat.2009.08.021.

[15] Guan Z., Jiang Y., Tanabasi Y., Huang H. Reinforcement mechanics of passive bolts in conventional tunnelling. International Journal of Rock Mechanics and Mining Science, vol 44: 625-636 (2007).

[16] Cai Y., Esaki T., Jiang Y.J. A rock bolt and rock mass interaction model. International Journal of Rock Mechanics and Mining Science, vol 41: 1055-1067 (2004).

[17] Xiao S.J., Chen C.F. Mechanical mechanism analysis of tension type anchor based on shear displacement method. J. Cent. South Univ. Technol., vol 15: 106-111 (2008), doi: 10.1007/s11771-0080021-z.

[18] Chen W.W., Ren F.F. Mechanical behavior of the bamboo-steel composite rock-bolt. Report 2006BAK30B02. Dunhuang Academy \& Cultural Relics Protection Center of Lanzhou University (2008). 
[19] Rong G., Zhu H.C., Zhou C.B. Testing study on working mechanism of fully grouted bolts of thread steel and smooth steel. Chin J Rock Mech Eng; 23(3): 469-475 (2004). 


\section{Figure captions:}

Figure 1: Main components of a laboratory pull-out test.

Figure 2: Stress distribution in an elementary length $d Z$ of the test sample.

Figure 3: Tri-linear bond-slip model and characteristic parameters.

Figure 4: Tri-linear bond-slip model for Chen and Ren's in situ pull-out test. Comparison between Ren et al.'s set of parameters and the set obtained by the authors.

Figure 5: Comparison between the experimental data (in situ pull-out test conducted by Chen and Ren, 2008) and the analytical approach offered in this paper and that proposed by Ren et al. [14] using a trilinear bond-slip model.

Figure 6: Comparison between the experimental data (Chen and Ren, 2008) and the complete new analytical approach (tri-linear bond-slip model).

Figure 7: Tri-linear bond-slip model for Rong et al.'s in situ pull-out test. Comparison between Ren et al.'s set of parameters and the set obtained by the authors.

Figure 8: Comparison between the experimental data (in situ pull-out test conducted by Rong et al., 2004) and the analytical approach offered in this paper and that proposed by Ren et al. [14] using a tri-linear bond-slip model. 


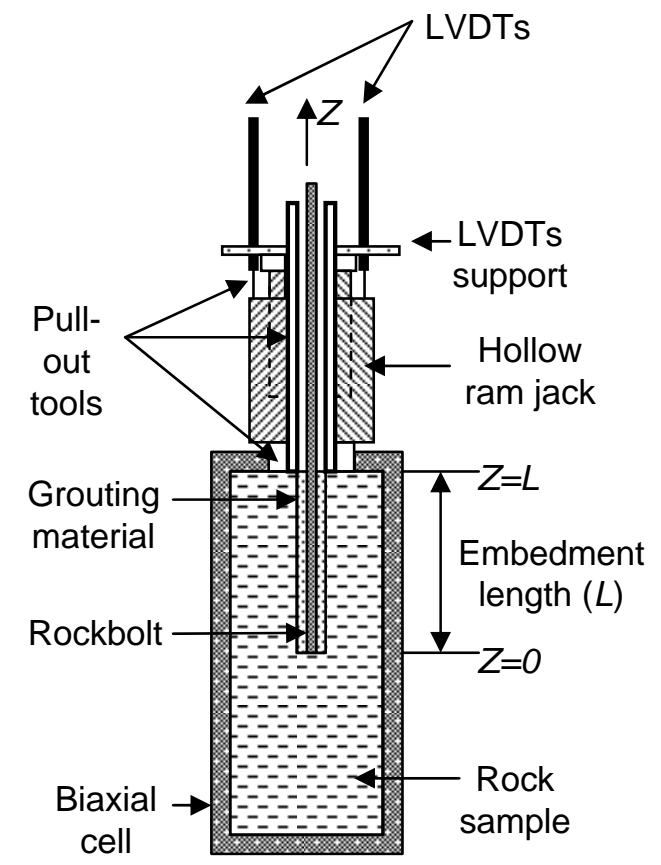




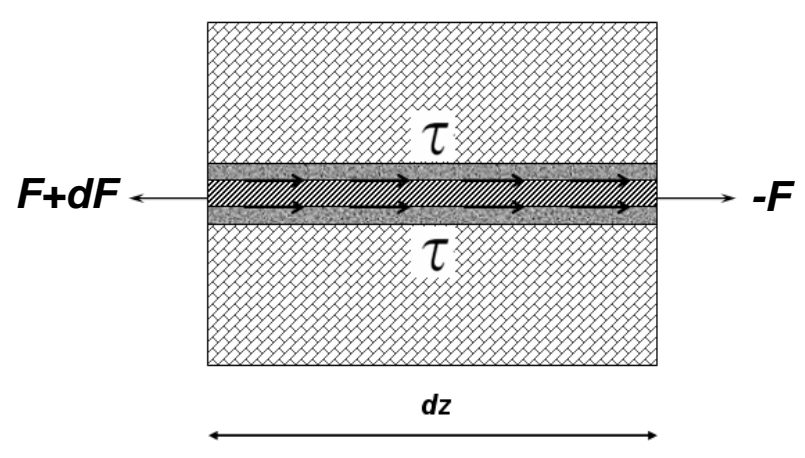




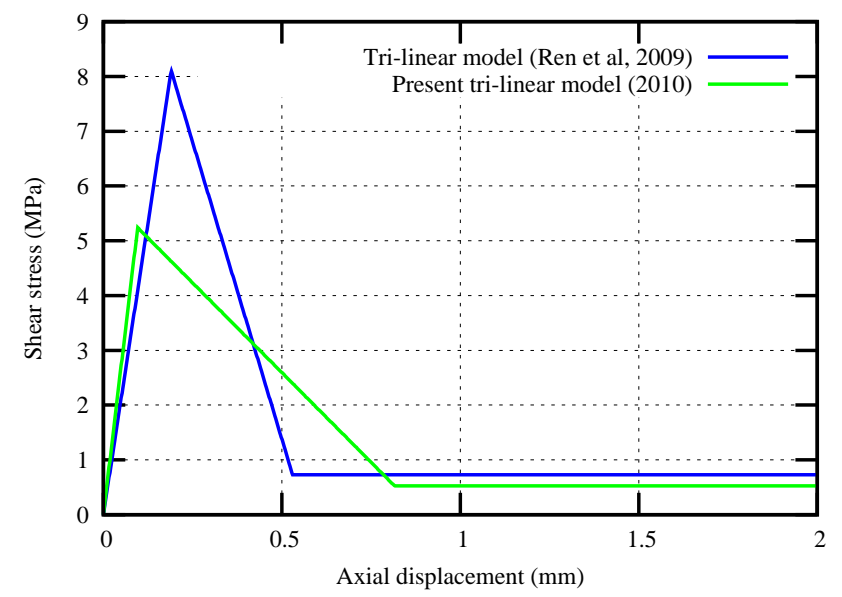




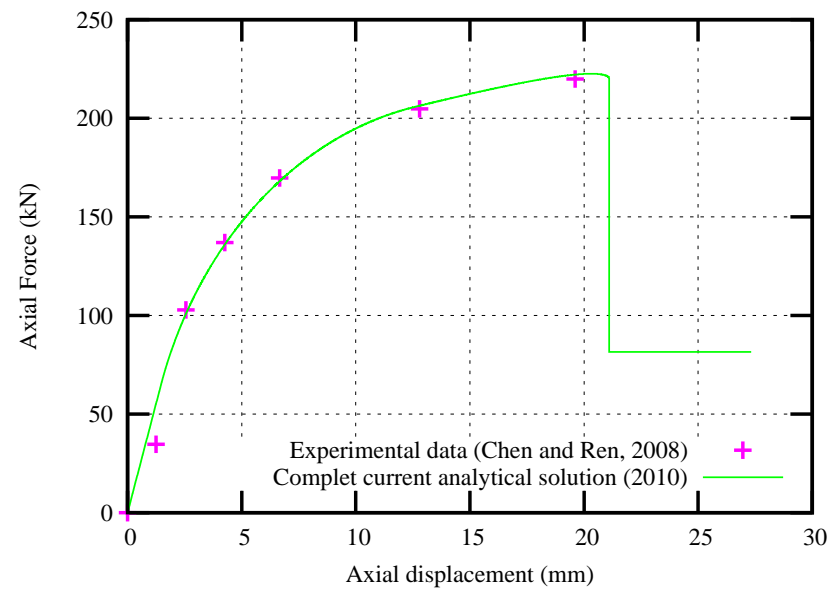




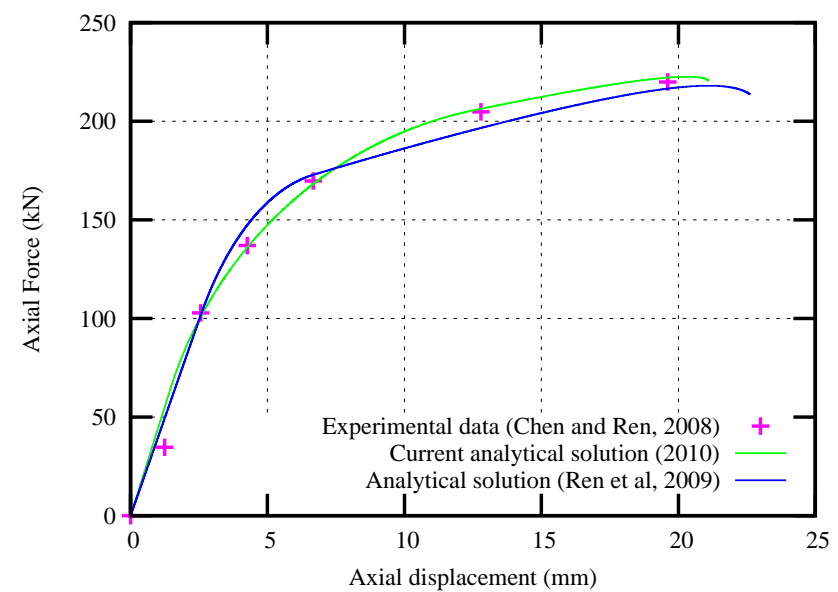




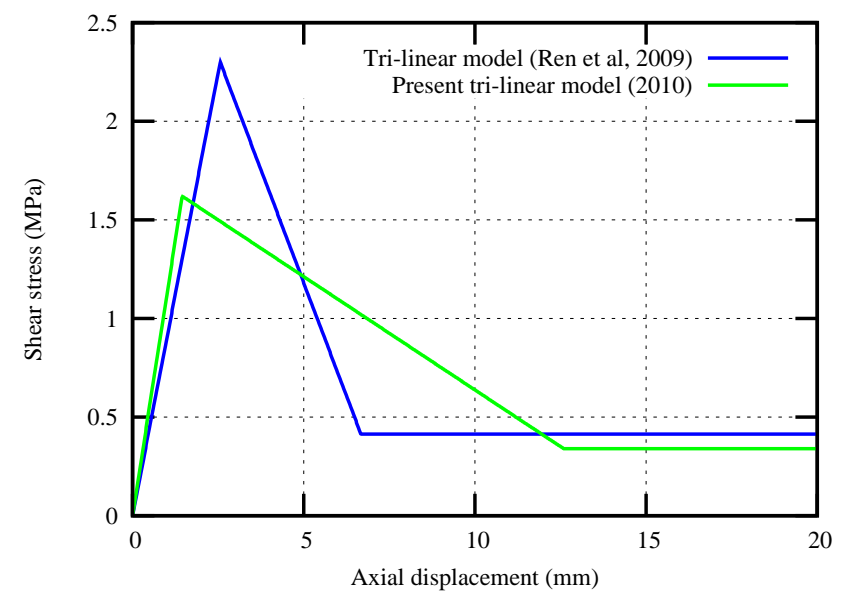




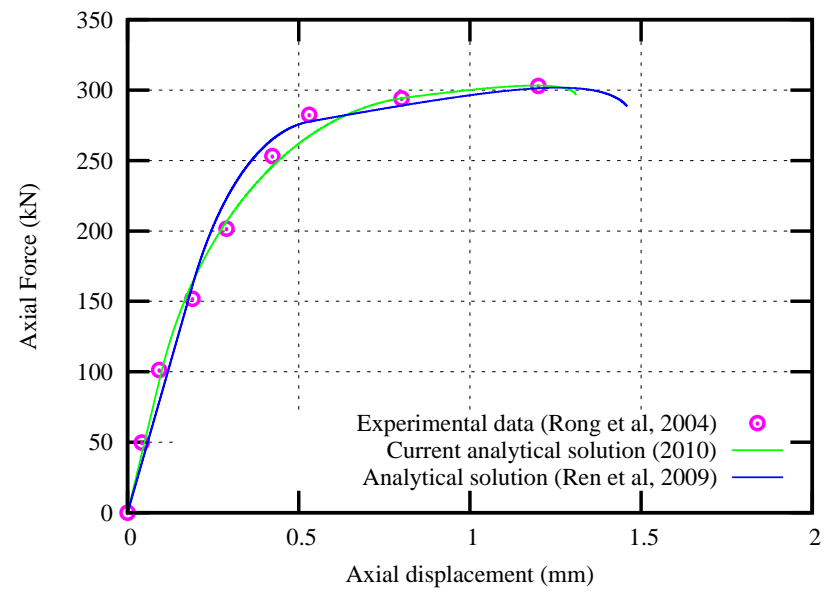

